\title{
Participação em Comunidades Sociais e a Prática Pedagógica com Modelagem Matemática: algumas relações
}

\author{
Participation in Social Communities and Pedagogical Practice with \\ Mathematical Modelling: some relations
}

\author{
Bárbara Cândido Braz* \\ ORCID iD 0000-0003-2280-3261 \\ Lilian Akemi Kato** \\ ORCID iD 0000-0001-8770-3873
}

\begin{abstract}
Resumo
Na perspectiva da Teoria Social da Aprendizagem (TSA) o processo de aprendizagem é compreendido como participação em comunidades sociais. À luz desse enfoque teórico, nesse artigo discutimos o papel das participações em diferentes comunidades sociais no processo de aprendizagem sobre a prática pedagógica com Modelagem Matemática de futuros professores de Matemática. Para tanto, exploramos o conceito de aprendizagem no âmbito da TSA, focando aspectos fundamentais para essa investigação, tais como os conceitos de comunidade social e de prática. A partir dessa discussão, articulamos esses pressupostos teóricos à aprendizagem sobre a prática pedagógica com Modelagem Matemática, recorrendo a descrições e análises de episódios de sala de aula e entrevistas desenvolvidas com estudantes de um quarto ano de Licenciatura em Matemática em uma universidade pública paranaense no ano letivo de 2015. As descrições são apresentadas de modo a relacionar a participação de duas licenciandas em comunidades sociais às aprendizagens das mesmas sobre a prática pedagógica com Modelagem Matemática. As reflexões decorrentes dessa investigação indicam a relevância da participação de futuros professores de Matemática em comunidades sociais cujas práticas aproximam comunidades escolares e aquelas constituídas no âmbito dos cursos de Licenciaturas para a decisão de incorporar a Modelagem Matemática às suas práticas pedagógicas.
\end{abstract}

Palavras-chave: Teoria Social da Aprendizagem. Aprendizagem Docente. Constelação de Práticas. Prática Pedagógica com Modelagem. Formação Inicial.

\begin{abstract}
From the perspective of Social Learning Systems, SLS, the learning process is understood as participation in social communities. In light of this theoretical approach, in this article we discuss the role of participation in different social communities in the learning process on the pedagogical practice with Mathematical Modelling of prospective Mathematics teachers. For this purpose, we explored the concept of learning within the SLS, focusing on key aspects for this research, such as the concepts of social community and community of practice. From this discussion, we articulated these theoretical assumptions to learning about pedagogical practice with Mathematical Modelling using descriptions and analysis of classroom episodes and interviews developed with

* Doutora em Educação para a Ciência e a Matemática pela Universidade Estadual de Maringá (UEM). Professora na Universidade Federal do Paraná (UFPR), campus de Jandaia do Sul, Jandaia do Sul, Paraná, Brasil. Endereço para correspondência: Rua Dr. João Maximiano, 426, Vila Operária, Jandaia do Sul, Paraná, Brasil, CEP: 86900-000. E-mail: barbarabraz@ufpr.br.

** Doutora em Matemática Aplicada pela Universidade Estadual de Campinas (UNICAMP). Professora Associada da Universidade Estadual de Maringá (UEM), Maringá, Paraná, Brasil. Endereço para correspondência: Av. Colombo, 5790, Maringá, Paraná, Brasil, CEP: 87020-900. E-mail: lilianakemikato@gmail.com.
\end{abstract}


fourth-year students of Mathematics Degree at a public university in Paraná in 2015. The descriptions are presented in order to relate the participation of two undergraduate students in social communities to their pedagogical learning practice with Mathematical Modelling. The reflections resulting from this research indicate the relevance of the participation of prospective Mathematics teachers in social communities, which practices bring school communities and those constituted within the Graduation courses the decision to incorporate the Mathematical Modelling into their pedagogical practices.

Keywords: Social Learning Systems. Learning for teaching. Constellation of Practices. Pedagogical Practice with Modelling. Initial training.

\section{A Modelagem Matemática no contexto da formação inicial de professores: um olhar sob as lentes teóricas da Teoria Social da Aprendizagem}

No cenário nacional, a década de 1980 demarcou mudanças no âmbito educacional. Em ambientes de ensino formal, as discussões quanto ao estabelecimento da Educação como um direito de todos reforçaram a necessidade de reflexões sobre o processo educativo com fundamentos teóricos em outras áreas, como a Psicologia e a Sociologia. De acordo com Fiorentini e Lorenzato (2009), no contexto do ensino e da aprendizagem da Matemática, passamos de um momento caracterizado por questionamentos do tipo "o que ensinar" (década de 1950 à 1970) para outro caracterizado pelas perguntas: "por que, para que e para quem ensinar?" (a partir de 1980), considerando ainda os aspectos sociais envolvidos nesses processos.

É nesse cenário que a Modelagem Matemática ${ }^{1}$, com cerne na Matemática Aplicada, emergiu como uma alternativa para se ensinar Matemática. Na medida em que demanda a articulação entre conceitos matemáticos e contextos com referência na realidade podemos afirmar que o uso da Modelagem na sala de aula, já naquele momento, conduzia ao rompimento com o paradigma educacional tradicional ${ }^{2}$. Isso porque requer dos envolvido nos processos de ensino e de aprendizagem o uso de argumentações matemáticas que possibilitam relações mais democráticas entre docente, discentes e saber. Desde então, a compreensão da complexidade das dimensões envolvidas no processo de educar matematicamente tem amparado as pesquisas sobre Modelagem no âmbito da Educação Matemática, estabelecendoa como "uma tendência relevante para a Educação Matemática, dada ao seu reconhecimento como tendência metodológica em documentos oficiais, como, por exemplo, no Estado do Paraná, nas Diretrizes Curriculares Estaduais - DCE”(OLIVEIRA; KLÜBER, 2018, p. 814).

Junto ao amadurecimento da comunidade sobre a Modelagem elucida-se a diversidade

\footnotetext{
${ }^{1}$ Doravante, utilizaremos o termo Modelagem para nos referir à Modelagem Matemática na perspectiva da Educação Matemática.

${ }^{2}$ Assumimos como paradigma educacional tradicional aquele que abarca práticas assimétricas entre os sujeitos envolvidos no processo educativo e que, em termos de práticas de sala de aula, consideram o(a) docente como o centro do processo educativo e os conteúdos curriculares desvinculados da sua historicidade.
} 
de teorias que respaldam essas pesquisas e as práticas docentes. Dessa forma, emergiram (e emergem) diferentes perspectivas (KAISER; SRIRAMAN, 2006) e concepções sobre a Modelagem na Educação Matemática. Em termos de práticas pedagógicas, embora as distintas concepções e perspectivas sobre o fazer Modelagem conduzam a diferentes ênfases numa atividade de sala de aula, como o desenvolvimento de conceitos matemáticos, de habilidades de resolução de problemas ou a análise da natureza dos modelos matemáticos (BARBOSA, 2007), os encaminhamentos quanto à sua organização didática têm aspectos comuns, isto é, convergências que podem ser reconhecidas "com base em estudos empíricos sobre o tema" (MEYER; CALDEIRA; MALHEIROS, 2011, p. 78).

Dentre as convergências, podemos mencionar a organização de estudantes em pequenos grupos que empreendem ações negociadas, orientados por um processo de investigação. Características essas que contribuem para o estabelecimento do que Skovsmose (2000) chama de cenário para investigação. Essas peculiaridades idiossincráticas à Modelagem promovem configuração específica para as aulas de Matemática, da organização arquitetônica da sala de aula às relações didáticas estabelecidas entre estudantes, docente e conhecimento, o que sugere também a incorporação de interações menos verticalizadas.

Diante dessas ponderações, entendemos que o desenvolvimento de atividades de Modelagem pode fomentar um ambiente de aprendizagem em que os alunos engajam-se, negociam significados sobre a situação, empreendem ações e compartilham um repertório de conhecimentos matemáticos, buscando interpretações ou compreensões para a investigação de situações problema com referência na realidade.

Considerando esses e outros argumentos, sua consolidação e os motivos favoráveis ao seu uso nos diferentes níveis de ensino, com vistas a uma educação matemática que ultrapassa o desenvolvimento de conteúdos curriculares amparou o estabelecimento de disciplinas específicas de Modelagem em cursos de licenciatura em Matemática (OLIVEIRA, 2016). Considerando essas ponderações e os resultados das investigações que evidenciam o distanciamento entre as pesquisas sobre Modelagem Matemática e suas práticas nas salas de aula da Educação Básica (CEOLIM, 2015), temos nos dedicado a investigar o processo de aprendizagem sobre a prática pedagógica com Modelagem no decorrer da formação inicial de professores de Matemática. As reflexões advindas dessas investigações se mostram pertinentes considerando que elas podem amparar o desenvolvimento de ações concernentes à Modelagem na formação inicial, bem como os processos formativos em Modelagem.

Nesse contexto, este estudo traz à baila compreensões sobre uma temática incipiente no âmbito da Modelagem na formação de professores de Matemática: o papel da participação 
em comunidades, às quais futuros professores de Matemática pertencem, no processo de aprendizagem sobre a prática pedagógica com Modelagem Matemática.

Ainda que o campo de pesquisa sobre a formação de professores que ensinam Matemática venha se consolidando na Educação Matemática, demandando inclusive um grupo de trabalho na Sociedade Brasileira de Educação Matemática (SBEM), pouco se tem investigado sobre a aprendizagem docente. De acordo com Vilas Boas e Barbosa (2016), a aprendizagem docente pode ocorrer no processo de formação inicial e continuada, mas não se restringe a elas, pois pode acontecer em diferentes contextos, inclusive naqueles que não foram delineados com propósitos pedagógicos de desenvolvê-la.

Nesse sentido, discutir a aprendizagem por meio das lentes teóricas da Teoria Social da Aprendizagem (TSA) é pertinente, posto que nessa perspectiva teórica o processo de aprendizagem é compreendido como algo que não decorre, exclusivamente, do processo de ensino enquanto atividade didatizada. De acordo com Lave e Wenger (1991, p. 43, tradução nossa), se muda "o foco analítico do indivíduo como alguém que aprende para o aprender como participação no mundo social e do conceito de processo cognitivo para a visão de prática social". Assim, o conceito de aprendizagem é compreendido como a participação na prática de comunidades sociais.

Essas comunidades sociais podem ser compreendidas como "estruturas sociais potenciais para desenvolver e compartilhar conhecimentos" (GARCIA; CYRINO, 2014, p. 2), pois consistem em ambientes construídos por meio de processos de negociação de significados entre seus membros, sustentados por um domínio que fundamenta essas relações. Nesse contexto, é pertinente afirmarmos que, na condição de estudante, no decorrer da vida escolar, aprendemos a ser professores, por meio da nossa participação nas práticas pedagógicas que, junto a outras práticas, caracterizam comunidades sociais escolares.

De forma análoga, o futuro professor aprende a ser professor de Matemática por meio das experiências vivenciadas na licenciatura, mesmo que elas não tenham sido planejadas com o intuito de ensinar aspectos sobre a prática pedagógica. A pesquisa de Mutti e Klüber (2018) mostra que a experiência na formação inicial é referenciada de forma unânime por professores participantes de um contexto de formação continuada como fator de grande influência nas suas práticas pedagógicas.

Sob essa perspectiva teórica, ao admitirmos a aprendizagem como um processo de participação, assumimos que ela ocorre na transformação das relações e formas de participação em um "sistema de atividades acerca do qual os participantes partilham compreensões sobre o que fazem e sobre o que isso significa nas suas vidas e comunidades" 
(LAVE; WENGER, 1991, p. 98, tradução nossa). Consideramos então, o curso de formação inicial como uma comunidade social da qual os futuros professores participam. Indissociavelmente, as transformações vivenciadas em uma comunidade social interferem nas participações das pessoas nas outras comunidades às quais pertencem, pois, enquanto sujeitos sociais, participamos de diferentes comunidades ao mesmo tempo, sustentadas em domínios também distintos e que, quando interconectadas, por meio de pessoas ou objetos comuns, tendem a formar o que Wenger (1998) denomina de constelação de práticas.

Num espectro de pesquisa sobre a aprendizagem docente sob o enfoque teórico da TSA, podemos citar as pesquisas desenvolvidas por Amado (2017) e Vilas Boas e Barbosa (2016), que tratam da aprendizagem do futuro professor e do professor que ensina Matemática, respectivamente. Nosso interesse, entretanto, se pauta especificamente no debate acerca da aprendizagem sobre a prática pedagógica com Modelagem Matemática. Mais particularmente, nos propomos a discutir a relação entre a participação de futuros professores de Matemática em diferentes comunidades sociais no decorrer da formação inicial e a aprendizagem sobre a prática pedagógica com Modelagem Matemática.

Para tanto, nas próximas seções exploraremos o conceito de aprendizagem na perspectiva da TSA, focando alguns aspectos fundamentais consonantes ao objetivo desse texto, tais como comunidade social e prática. A partir dessa discussão, articulamos esses pressupostos teóricos à aprendizagem sobre a prática pedagógica com Modelagem Matemática recorrendo a descrições e análises de episódios de sala de aula e entrevistas desenvolvidas com futuras professoras de Matemática que vivenciaram a disciplina de Modelagem em um curso de licenciatura em uma universidade pública, no ano letivo de 2015.

\section{Participação em comunidades sociais e a aprendizagem sobre prática pedagógica com Modelagem}

Como a participação em determinados contextos sociais permite o processo de aprendizagem? Essa questão e as respostas para ela são apresentadas por Lave e Wenger (1991) a partir de reflexões sobre estudos etnográficos desenvolvidos pela antropóloga social Jean Lave na África Ocidental, na década de 1980. Lave (1988) investigou práticas de aprendizes de alfaiataria e buscou compreender como aqueles sujeitos tornavam-se alfaiates mesmo sem que alguém os ensinasse a profisssão, na condição de professores.

A pesquisadora concluiu que a análise que culminaria nas respostas para a questão posta anteriormente deveria voltar-se às relações entre os aprendizes, incluindo as mudanças 
nas suas formas de participação na prática daquele grupo específico de alfaiates. De acordo com Lave (2015, p. 40, tradução nossa), foi possível compreender que "os aprendizes estão engajados (com outros) em aprender o que eles já estão fazendo - um processo multifacetado, contraditório e interativo". Nesse sentido, Lave e Wenger (1991) afirmam que é possível compreendermos como as pessoas aprendem ao considerarmos que somos participantes, mais ou menos plenos, na prática de comunidades sociais. Assim, de acordo com os autores, a aprendizagem é a participação em comunidades sociais.

A compreensão sobre o conceito de comunidade social, entretanto, não é algo intuitivo. Essa noção foi aprofundada por Wenger (1998) ao sistematizar a TSA. De acordo com o autor, a aprendizagem é participação no que ele denomina de comunidade de prática $(\mathrm{CoP})$ e nem toda comunidade é uma CoP. Para que uma comunidade seja concebida como CoP, é necessário que existam uma comunidade, um domínio e uma prática que a caracterizem, além de alguns elementos que definem a prática como fonte de coerência da comunidade. Assim, assumimos que uma comunidade pode ser concebida como uma comunidade social se reconhecermos nela um domínio, uma comunidade e uma prática.

A comunidade, de acordo com Wenger (1998), incentiva as aprendizagens a partir da interação regular entre um grupo de pessoas. Isso não significa que os membros de uma comunidade compõem um agrupamento homogêneo. No entanto, podemos afirmar que as relações mantidas na comunidade pelos seus membros, ainda que nem sempre sejam harmoniosas, serão sempre pautadas em interesses comuns, que constituem a razão de existir dessa comunidade, o que Wenger (1998) chamou de domínio.

Assim, o domínio de uma comunidade não é um conjunto de problemas determinado antes da constituição da mesma, haja vista que envolve questões que os membros dela vivem e compartilham. Trata-se, portanto, de um corpo de conhecimentos que acompanha a evolução da CoP no curso da sua existência e do mundo social em que ela se insere. Em um contexto de formação continuada de professores sobre Modelagem Matemática, por exemplo, pode ser que uma CoP seja constituída. Nesse âmbito, as ações concernentes à Modelagem sejam estudos teóricos, desenvolvimento de tarefas e atividades de Modelagem, sistematização de práticas pedagógicas, dentre outras - fundamentarão o domínio dessa comunidade de pessoas interessadas em aprender sobre Modelagem. Ao mesmo tempo, as ações descritas anteriormente, ainda que possam fazer parte de atividades empreendidas em outras comunidades, como o de uma $\mathrm{CoP}$ de formação de professores, podem não representar o domínio dessa comunidade, caso essas ações não constituam seu âmago. 
A prática da comunidade, por sua vez, pode ser compreendida como "um processo de aprendizagem que contempla o conhecimento específico desenvolvido, mantido e partilhado pelos membros de uma CoP, e que é próprio dessa comunidade" (GARCIA, 2014, p. 31), portanto, refere-se ao modo como experienciamos o mundo e produzimos significados às coisas que fazemos. Nesse sentido, ela abarca o repertório compartilhado pela comunidade, decorrente do engajamento mútuo dos seus membros.

Assim, podemos afirmar, de acordo com Wenger (1998), que a prática diz respeito ao conhecimento que determinada comunidade social cria, mantém e compartilha, por meio de um processo de negociação de significados, que inclui aspectos implícitos - o que não se diz e explícitos - o que se diz - como: linguagem, instrumentos, documentos, etc., que são tomados pelos membros como referência para nortear suas ações num domínio específico, como no exercício da sua profissão. A prática, enquanto fonte de coerência de uma comunidade social, portanto, é sempre uma prática social.

Particularmente, nesse texto, a fim de utilizarmos esse arcabouço teórico para compreendermos o processo de aprendizagem sobre a prática pedagógica com Modelagem, fazemos uma flexibilização do conceito de CoP. Tal como Vilas Boas e Barbosa (2016), optamos por utilizar o conceito de comunidade social, pois, para que possamos falar na existência de uma $\mathrm{CoP}$, para além das características descritas anteriormente, é preciso que existam empreendimentos articulados entre seus membros, decorrentes do engajamento mútuo na prática da comunidade, criando um repertório compartilhado. Características essas definidoras da prática como fonte de coerência da comunidade.

Nesse estudo, olhamos para comunidades, constituídas em alguns contextos vinculados a um curso de Licenciatura em Matemática de uma universidade pública paranaense, como comunidades sociais, dentre os quais: uma disciplina de Modelagem Matemática; o Programa Institucional de Bolsas de Iniciação à Docência (PIBID); escola pública de Educação Básica (nessa comunidade, a participação dos futuros professores se deu por meio do desenvolvimento do Estágio Supervisionado obrigatório); de contratos profissionais provisórios por processo seletivo simplificado (PSS); do desenvolvimento de Trabalho de Conclusão de Curso (TCC) ou mesmo pelo PIBID.

Nesse sentido, não seria viável utilizar o conceito de $\mathrm{CoP}$, na medida em que não teríamos subsídios para analisar sua existência em todos esses casos, considerando que acompanhamos apenas a constituição da comunidade na disciplina de Modelagem, como mostramos em estudo anterior (BRAZ, 2017). Nossa participação nessa comunidade social 
permitiu que analisássemos os processos de negociação de significados empreendidos pela turma sobre a prática pedagógica com Modelagem Matemática na Educação Básica.

Essa comunidade social, constituída na disciplina de Modelagem, diferencia-se fundamentalmente das outras comunidades sociais, como a do PIBID ou mesmo uma comunidade de alfaiates. Isso porque ela se desenvolveu num ambiente de ensino formal, em que seus membros não se uniram, inicialmente, por seus interesses, mas pela obrigatoriedade dessa disciplina para o curso de Licenciatura em Matemática naquela universidade. Ao mesmo tempo, pesquisadores (MATOS, 1999; WINBOURNE; WATSON, 1998; BRAZ; KATO, 2015) já evidenciaram as potencialidades em usar elementos desse arcabouço teórico como ferramenta para analisar relações didáticas em ambientes formais de ensino.

Também de forma ímpar à constituição das demais comunidades, essa aqui constituída na disciplina de Modelagem Matemática teve seu domínio sustentado na Modelagem Matemática. Mais especificamente, o domínio que a sustentou foi a prática pedagógica com Modelagem. Tal como a prática de uma comunidade social, a prática pedagógica na perspectiva educacional assumida, é compreendida como uma prática social, pois situa-se histórica e socialmente em determinados contextos. As práticas pedagógicas, entretanto, "se organizam para concretizar determinadas expectativas educacionais" (FRANCO, 2016, p. 541) e, carregadas de intencionalidade, demandam planejamento e ações científicas "sobre o objeto com vistas à transformação da realidade social" (ibid).

Considerando essa perspectiva, ainda de acordo com Franco (2016), a prática docente é uma prática pedagógica se o professor, no exercício de sua prática docente, se movimenta pedagogicamente por meio de pelo menos "dois movimentos: o da reflexão crítica de sua prática e o da consciência das intencionalidades que presidem suas práticas" (FRANCO, 2016, p. 543). Esses movimentos, por sua vez, são envoltos pelos condicionantes sociais, circunstâncias de formação, dentre outros aspectos que constituem as práticas pedagógicas. É nesse contexto teórico, no qual nos referimos à prática pedagógica com Modelagem: uma prática imbuída de intencionalidade, reflexão, amparada na prática educativa e que tem, na Modelagem Matemática na perspectiva da Educação Matemática, uma possibilidade para desenvolver o processo de educar matematicamente estudantes.

No curso da existência da comunidade social constituída na disciplina de Modelagem Matemática, ao debaterem sobre aspectos da prática pedagógica com Modelagem os futuros professores recorreram a experiências sobre suas participações nas práticas de outras comunidades às quais pertenciam (ou pertenceram). Essas participações em outras 
comunidades também ampararam, portanto, os processos de negociação de significados sobre a prática pedagógica com Modelagem.

O processo de negociação de significados, de acordo com Wenger (1998) combina elementos da participação dos membros na comunidade e da reificação. Participação e reificação são, portanto, processos complementares (WENGER, 1998). O processo de participação denota a combinação entre o fazer, falar, pensar o senso de pertença à CoP, ou seja, os caminhos na trajetória de participação (CYRINO, 2009). O processo de reificação, por sua vez, concerne a uma maneira de dar forma e "congelar" a experiência, produzir abstrações, histórias que reificam a prática de um grupo social (FERNANDES, 2004).

Para além do discurso dos membros de uma comunidade social, artefatos como documentos, objetos, conceitos, representam reificações de uma comunidade. Eles não denotam acordo, mas sim a negociação sobre algo. Esses artefatos, quando pertencem a diferentes comunidades ao mesmo tempo e têm o potencial de coordenar as diversas perspectivas dessas comunidades, são considerados por Wenger (1998) como objetos de fronteira. Da mesma forma, o trabalho de interconectar perspectivas entre comunidades pode ser desenvolvida por membros de fronteira, brokers ${ }^{3}$. Pode-se afirmar que esse trabalho requer a capacidade de introduzir elementos de uma prática em outra. Para tanto, é necessário conectar as experiências de multiafiliação e as possibilidades de negociação inerentes à participação (WENGER, 1998). Participação e reificação podem criar, dessa forma, continuidades por meio das suas fronteiras, como ilustra a Figura 1.

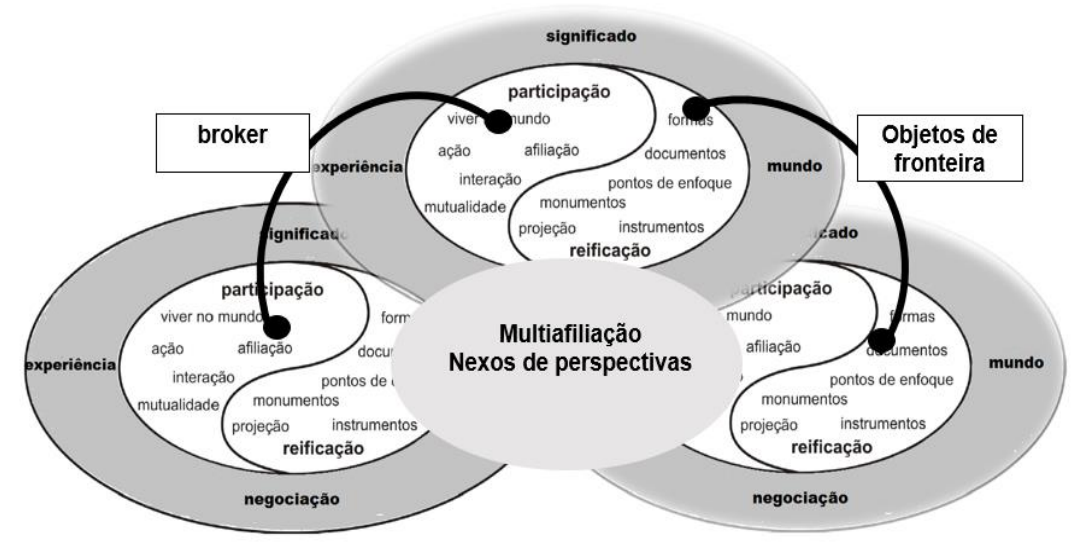

Figura 1 - Participação e reificação como conexões

Fonte: BRAZ (2017) - Adaptado de Wenger (1998, p. 105, tradução nossa).

A Figura 1 evidencia o papel dos objetos de fronteira e o papel de intermediação, pelos brokers, no estabelecimento de relações entre comunidades, denotando o que Wenger (1998) denomina de constelação de práticas. Segundo o autor, o termo constelação é

\footnotetext{
${ }^{3}$ A fim de manter o significado do termo, utilizaremos a expressão na língua inglesa.
} 
utilizado para denotar um sistema cujos objetos que o constituem podem não ter a mesma forma, tamanho ou não ser tão próximos geograficamente, mas que estão interconectados e cuja visão de conexão depende da perspectiva de quem olha.

A construção de constelações de práticas é dinâmica e merece ser analisada sob duas perspectivas. Primeiro, um membro pode participar de várias comunidades ao mesmo tempo, gerando a necessidade de interconectar as diferentes perspectivas das comunidades das quais participa, moldando cada comunidade a que pertence. Em segundo lugar, uma mesma comunidade pode pertencer a diferentes constelações. No contexto dessa investigação, assumimos que constelações de práticas puderam ser reconhecidas nos processos de negociação de significados mantidos pelos membros da comunidade social constituída na disciplina de Modelagem. Ao manter negociações de significados sobre a prática pedagógica com Modelagem nessa comunidade social, seus membros recorreram a práticas de outras comunidades sociais às quais pertenciam, como o PIBID e a comunidade escolar. Dessa forma, explicita-se uma constelação de práticas constituída pelas comunidades sociais do PIBID, escolar e aquela constituída na disciplina de Modelagem.

Fundamentadas nesses pressupostos da TSA e, no âmbito da formação de professores, pautadas em Vilas Boas e Barbosa (2016, p. 1103), assumimos a "aprendizagem docente como a mudança nos padrões de participação do professor na prática pedagógica escolar" e “em outras práticas, que podem repercutir em mudanças de participação na prática pedagógica escolar". Especificamente no contexto dessa investigação compreendemos, então, o processo de aprendizagem como a mudança nos padrões de participação das futuras professoras nas comunidades sociais das quais participavam, que constituíram constelação de práticas, particularmente no que diz respeito à prática pedagógica com Modelagem Matemática.

Nessa perspectiva, convém salientar que as participações das futuras professoras em comunidades sociais com domínios e práticas distintas, permitiram aprendizagens também distintas. De acordo com Vilas Boas e Barbosa (2016, p. 1097) podemos falar sobre dois tipos de aprendizagem: a aprendizagem na docência, concernente à "mudança nos padrões de participação na prática pedagógica em que este exerce a tarefa do ensino" e a aprendizagem para a docência, na qual ocorrem "mudanças nos padrões de participação em outras práticas que podem provocar a mudança na participação na prática pedagógica escolar”.

Depreende-se disso a relevância de situar as comunidades consideradas nesse texto, em termos das que a elas se relacionam, por meio dos brokers e dos objetos de fronteira. 


\section{Caminhos da pesquisa: a participação em comunidades sociais e a prática pedagógica com Modelagem Matemática ${ }^{4}$}

Seguindo o propósito de discutir o papel das participações em comunidades sociais no processo de aprendizagem sobre a prática pedagógica com Modelagem de futuros professores de Matemática, essa investigação insere-se no campo da pesquisa qualitativa. Com essa compreensão, essa pesquisa se caracteriza como tal na medida em que os dados foram construídos, coletados e interpretados considerando sua dinamicidade e as novas questões emergentes nessa trajetória. Sobretudo, as configurações da pesquisa não nos permitiram fazer inferências previamente às interpretações e às significações dos fatos, ou generalizações, pois se tratam de análises locais, que visam à compreensão dessa situação em específico. Com referência em Garnica (2012), entendemos que essas são características de uma pesquisa qualitativa.

Com vistas a cumprir o objetivo enunciado, nos embasamos nas descrições e análises de dados emergentes de ações empreendidas por estudantes do último ano de um curso de Licenciatura em Matemática de uma universidade pública paranaense, no ano letivo de 2015. Essas estudantes cursavam, naquele período, uma disciplina de Modelagem Matemática na perspectiva da Educação Matemática. Dessa disciplina, com carga horária de sessenta e oito horas aula, participaram nove estudantes, citadas com nomes fictícios, o professor regente denominado de professor - e a primeira autora desse texto.

No início do ano letivo de 2015, juntamente com a primeira autora, o professor regente da disciplina organizou-a de forma a abarcar propostas que permitissem reflexões e aprendizagem para a docência com Modelagem. Ou seja, as ações previstas e desenvolvidas no âmbito da disciplina envolveram estudos como, por exemplo, sobre o que é Modelagem, como empreendê-la na sala de aula, por que utilizá-la para ensinar Matemática, os devidos encaminhamentos didáticos, motivos para usá-la ou não, sua inserção no currículo escolar, dentre outros aspectos. Ao todo: i) quatro atividades de Modelagem foram conduzidas pelo professor, sob diferentes configurações, nas quais o processo de problematização das situações foram empreendidos ou apenas pelo professor ou por alunos e professor, no decorrer de trinta e duas horas aula; ii) cinco textos sobre Educação Matemática e Modelagem foram debatidos em sala de aula, ocupando uma carga horária de vinte horas aula e; iii) três tarefas de Modelagem foram construídas e desenvolvidas pelos estudantes no âmbito da própria

\footnotetext{
${ }^{4}$ Essa pesquisa foi aprovada pela Comissão de Ética em Pesquisa (CEP) pelo parecer número 1.345.405; e com Certificado de Apresentação para Apreciação Ética (CAAE) número 47671015.7.0000.0104.
} 
disciplina, no decorrer de dez horas aula.

As ações previstas e desenvolvidas na disciplina, portanto, não abarcaram ações que possibilitavam aprendizagens $n a$ prática pedagógica com Modelagem. Não foram previstas ações em que os futuros professores deveriam orientar atividades de Modelagem na Educação Básica, na condição de professores, como indicam pesquisas sobre formação de professores em Modelagem (ALMEIDA; SILVA; VERTUAN, 2012; BRAZ, 2017; OLIVEIRA, 2017).

Todas as aulas foram registradas em áudio e vídeo a fim de acompanhar os processos de negociação de significados empreendidos na comunidade que se constituía. Além desses registros, os materiais produzidos pelos estudantes foram considerados no processo analítico. Esses registros descrevem o repertório compartilhado por essa comunidade no que se refere à aprendizagem sobre a prática pedagógica com Modelagem Matemática.

Notadamente, o repertório dessa comunidade social foi marcado por discursos advindos da participação dos futuros professores em outras comunidades às quais pertenciam, o que vai ao encontro do que dizem Lave e Wenger (1991, p. 98, tradução nossa) ao afirmarem que "uma comunidade de prática é um conjunto de relações entre pessoas, atividade e mundo, ao longo do tempo e em relação com outras comunidades de prática tangenciais e com elementos comuns". Na medida em que os sujeitos participaram de comunidades, cujos objetivos abarcam de alguma forma o seu desenvolvimento profissional, as suas compreensões sobre a prática pedagógica com Modelagem foram (res)significadas.

Ainda que os processos de negociação de significados mantidos por todos esses membros na comunidade da disciplina sejam considerados, a fim de empreender a discussão nesse texto elegemos as participações de duas futuras professoras, Clara e Ana, nessa e em outras comunidades às quais pertenciam, para discutirmos a relação entre a aprendizagem sobre a prática pedagógica com Modelagem e a participação em comunidades sociais. Isso porque dentre os membros da comunidade constituída na disciplina de Modelagem, apenas Ana desenvolveu atividades de Modelagem Matemática no âmbito dos Anos Finais do Ensino Fundamental e no Ensino Médio na condição de professora, por meio do PIBID e do desenvolvimento do TCC e Clara era professora (contratada por meio de PSS) no mesmo nível de ensino experienciado por Ana, há mais de um ano naquela ocasião, e relatou tentativas de desenvolver atividades de Modelagem na sua prática profissional.

Nesse sentido, ambas futuras professoras tiveram oportunidades de refletir sobre a prática pedagógica com Modelagem por meio das suas experiências com Modelagem na docência e não apenas para a docência. Sobretudo, ambas exerceram papeis representativos na comunidade, na medida em que levaram à baila aspectos importantes sobre a prática 
profissional docente e os articularam à prática pedagógica com Modelagem, marcando suas posições e participações nessa e em outras comunidades às quais pertenciam, ou seja, desempenharam papéis de brokers.

Em comum, as futuras professoras exerceram papéis de brokers ao interconectaram a comunidade social constituída na disciplina de Modelagem a comunidades formadas no contexto de escolas públicas. As comunidades sociais das quais elas participaram, no entanto, estão embasadas em domínios distintos e isso têm implicações para os seus posicionamentos nas comunidades das quais participavam e na forma como buscaram interconectar as práticas dessas comunidades. No caso de Ana, a comunidade social escolar esteve vinculada a contextos de atividades formativas, o PIBID e o desenvolvimento do seu TCC. Sendo assim, as atividades empreendidas por Ana, que a colocavam no lugar de aprendiz da profissão, foram supervisionadas e tinham como objetivo central o seu desenvolvimento profissional. No caso de Clara, a sua participação em uma comunidade social escolar se deu por meio de um contrato profissional. Dessa forma, o objetivo central da sua prática naquela comunidade era o exercício profissional, sem supervisão, no papel de professora. Sobretudo, Clara já era formada em Engenharia e iniciou sua prática profissional docente antes do ingresso no curso de licenciatura em Matemática. Esse foi, inclusive, o motivo pela qual decidiu cursar a licenciatura.

O fato da prática profissional de Clara anteceder a formação inicial tem implicações para sua participação e engajamento no curso e, consequentemente, na disciplina de Modelagem. Concomitantemente, o fato de já atuar profissionalmente gerou obstáculos quanto à sua participação em outras atividades pedagógicas vinculadas ao curso. Segundo Clara, o fato de trabalhar o dia todo e estudar no período noturno tornou inviável sua participação em atividades formativas como o PIBID ou outros programas de formação, como o desenvolvimento de iniciação científica. Esse pode ser um dos motivos pelos quais nos processos de negociação de significados empreendidos na comunidade da disciplina de Modelagem, ao buscar ilustrações e fazer reflexões sobre sua prática docente, Clara recorre à episódios que rementem à prática da comunidade escolar da qual era participante:

Clara: Assim... eu acho que ali na escola, entre os professores de Matemática, ninguém comenta sobre Modelagem Matemática. Até é feito. Não vou falar pra você que não é feito. Não é uma coisa nova esse tipo de investigação, mas eu acho que com o nome M-O-D-E-L-AG-E-M, sendo a Modelagem essa investigação e essa problematização, eu acho que isso somente quem fez a disciplina de Modelagem, no curso de Matemática, tem essa noção. (Entrevista 1, junho-2015).

Tal declaração de Clara foi feita ao ser questionada se ela conhecia a Modelagem 
Matemática antes do início da disciplina de Modelagem no curso de Licenciatura. Sua afirmação indica que ela identifica ações práticas na comunidade escolar, da qual é membro, ações que se aproximam às da Modelagem Matemática, o que denota a constituição do que Tardif (2004) denomina de saberes experienciais. Ao mesmo tempo, parecem explicitar a ausência de saberes denominados por Tardif (2004) de saberes da formação profissional; nesse caso, concernentes à prática pedagógica com Modelagem Matemática.

A compreensão sobre a prática com Modelagem Matemática na comunidade escolar da qual Clara faz parte, nesse sentido, parece conflitar com a compreensão sobre a prática pedagógica com Modelagem que constitui o domínio da comunidade constituída na disciplina de Modelagem. Inferimos que isso esteja relacionado ao fato de que ambas as comunidades, interconectadas por meio de Clara, se amparam em domínios diferentes. Decorre disso que a participação de Clara na comunidade da disciplina, quando recorre às suas experiências profissionais evidencia resistências quanto à incorporação da prática com Modelagem à prática profissional. Dentre essas, já identificadas por Ceolim (2015), ressaltamos a que se refere ao cumprimento do currículo escolar. Esse documento compreendido por Clara como algo fechado e que precisa ser cumprido de forma linear, motivou episódios de negociação de significados na comunidade da disciplina. No decorrer de uma aula em que a turma discutia sobre a inserção da Modelagem Matemática na escola, enquanto alguns estudantes defendiam seu uso, já previsto nos documentos curriculares do Estado do Paraná, Clara argumentou:

Clara: A matemática é muito sequencial, então, de repente, se você pular algum conteúdo que não deu tempo de ver, então... por que o que acontece com a Modelagem? [...] o professor faz o plano de aula dele dessa forma, pensando no conteúdo que ele tem que aplicar, porque senão no próximo ano o aluno vai ter dificuldades. (Gravação em áudio e vídeo de aula - maio/2015).

Esse posicionamento evidencia a forma como a futura professora traz ao debate na comunidade da disciplina um objeto pertencente à comunidade escolar: o currículo. Nesse sentido, o currículo escolar pode ser compreendido como um objeto de fronteira que, nesse caso, alinha duas comunidades sociais. Sincronicamente, o currículo escolar, aqui compreendido como um objeto de fronteira que conecta as duas comunidades sociais, fez com que outros estudantes recorressem às suas vivências na escola, por meio dos Estágios Supervisionados obrigatórios para o debate sobre essa temática.

Tal como Clara, outros futuros professores afirmaram que o currículo escolar é um obstáculo à inserção da Modelagem na Educação Básica, reificando dois aspectos: i) o de que a sua linearidade é rompida e, portanto; ii) torna mais difícil o seu cumprimento. Ao empreender essa discussão, é salutar explicitarmos que os futuros professores se amparavam 
nas suas participações na comunidade escolar, por meio dos Estágios Supervisionados obrigatórios.

Nesse contexto, as reflexões dos alunos vão ao encontro dos apontamentos de Wenger (1998) e de Schommer (2005), ao afirmarem que, numa mesma posição, nesse caso de professores, uma pessoa pode ver sua profissão como algo temporário e isso influencia sua participação naquele contexto. Os futuros professores pareceram vislumbrar o momento de Estágio Supervisionado como um espaço profissional transitório, na medida em que existiam tanto restrições de tempo para exercício da profissão, quanto restrições impostas pela instituição ou professor(a) supervisor(a) naquela comunidade.

Clara, entretanto, ao referenciar suas experiências na Educação Básica durante o Estágio Supervisionado, ainda que trouxesse ao debate aspectos que dizem respeito a uma participação transacional (WENGER, 1998) relacionada ao Estágio, pareceu reconhecer sua participação na comunidade escolar como professora no exercício da profissão e argumentou:

Clara: Você (professor) acredita que dá pra substituir todas essas aulas que a gente tá dando, que a gente tá dando do mesmo jeito [...] no tradicional, por só situações problemas e tal e o aluno já vai conseguir compreender o conceito de matriz? Ele já vai conseguir fazer a multiplicação e tal, sem antes ter visto o método tradicional?[...] Eu acho que fica difícil a gente não seguir essa burocracia aí que a gente tem ... que vem das DCE... [...] Mas na questão da matriz, professor, eu penso que tem que trabalhar primeiro essa parte tradicional com eles pra depois dar um problema pra eles resolverem, entendeu?

(Gravação de áudio e vídeo de aula - outubro/2015, grifos nossos).

Nesse contexto, a tentativa de alinhar duas comunidades por meio de um objeto de fronteira, o currículo, gerou conflitos em relação à forma como esse mesmo objeto era incorporado ao domínio das duas comunidades, a escola e aquela constituída na disciplina de Modelagem. Se, por um lado, as negociações mantidas na comunidade da disciplina tenderam a considerá-la como uma prática pedagógica possível e alinhada ao currículo da Educação Básica, inclusive prevista nas DCE; por outro lado, na comunidade escolar, a prática com Modelagem foi compreendida como um obstáculo ao cumprimento desse documento.

Para além das questões curriculares, outro aspecto apareceu de forma conflitante entre as duas comunidades, marcando a participação de Clara. O trecho sublinhado da sua fala manifesta a argumentação de que primeiro o professor deve ensinar conceitos desvinculados de situações reais ou semirreais e, só depois, mostrar a aplicação deles em situações dessa natureza. Esse posicionamento demarcou, no contexto de fala, uma tentativa de adaptação da Modelagem à uma prática pedagógica tradicional; mais especificamente, a busca por aproximá-la do que Skovsmose (2000) chama de paradigma do exercício, ou seja, utilizar situações em que os estudantes já sabem que conceitos utilizarão para resolver a tarefa. A 
última fala também aponta traços de uma escola pautada em práticas pedagógicas tradicionais e que, portanto, fundamentalmente, não tem espaço para o desenvolvimento de ambientes de aprendizagem investigativos, em que situações não previstas pelo professor podem ocorrer.

Essa argumentação se contrapõe à aspectos reificados pela comunidade da disciplina de Modelagem, em que os membros, ao mencionarem motivos favoráveis ao seu uso, ressaltam seu aspecto investigativo, como afirma Ana:

Ana: [...] eu passei por isso. Quando a gente fez as atividades, a gente teve que ir atrás dos dados. A gente ficava investigando. Eu acho melhor, porque você aprende bem mais do que o professor passando no quadro [...] eu penso: que conteúdo que dá pra ser trabalhado com esse problema? Tento explorar ao máximo todas as possibilidades de conteúdos. Eu lembro do PIBID, quando a gente fazia e explorava bastante (com os alunos). Das aulas de Modelagem eu penso bastante nas discussões que fazíamos se valia a pena o jeito pra ser trabalhado, com que turma pode ser trabalhada determinada atividade?

(Entrevista 5 - janeiro, 2016).

Elegemos essa fala de Ana como representativa por demarcar tanto a sua compreensão sobre a pertinência da prática pedagógica com Modelagem nas aulas de Matemática, quanto a sua participação numa constelação de práticas que alinha, explicitamente, a comunidade do PIBID e aquela constituída na disciplina de Modelagem. Acerca do alinhamento entre ambas as comunidades, numa constelação de práticas, Ana exerceu o papel de broker, na medida em que retomou, na comunidade da disciplina, suas vivências no PIBID atribuindo a elas parte da responsabilidade por ser sentir segura em utilizar Modelagem para ensinar Matemática.

De acordo com Ana, sua principal motivação para o ingresso no PIBID quando estava no segundo ano do curso foi conhecer, desde cedo, a sala de aula. Por meio do PIBID, a aluna teve a oportunidade de estudar e orientar atividades investigativas na Educação Básica. Segundo ela, essas experiências conferiram-lhe segurança, pois sempre esteve acompanhada por outros alunos do programa e por professores formadores. Foi no PIBID que Ana conheceu a Modelagem e decidiu desenvolver seu TCC nessa área. A futura professora relatou ter vivenciado uma atividade de Modelagem, na condição de aluna, que a incentivou ao ponto de querer investigar aspectos sobre a prática pedagógica com Modelagem no Ensino Médio. Dessa vez, orientando a mesma atividade vivida no PIBID, agora na condição de professora.

Sobre o desenvolvimento da atividade de Modelagem por Ana em decorrência do seu TCC, é relevante informar que, para além da familiaridade com a tarefa proposta, a estudante relatou ter escolhido a escola e a turma que eram parceiros no PIBID. Logo, já existia, na ocasião do desenvolvimento das atividades para o TCC, o reconhecimento de Ana como participante daquela comunidade e que desenvolvia práticas investigativas nas aulas de Matemática naquela escola devido ao seu vínculo com o PIBIB. 
O repertório de práticas pedagógicas do qual Ana dispunha, por sua vez, decorrente das suas afiliações nas comunidades sociais mencionadas, lhe permitiram antever e planejar algumas ações de sala de aula. A atividade conduzida por ela seguiu os mesmos encaminhamentos didáticos empreendidos pelo professor da disciplina de Modelagem ao orientar atividades dessa natureza. Concomitantemente, o fato de já ter vivenciado a atividade na condição de aluna, no PIBID, pareceu assegurar-lhe confiança sobre os possíveis encaminhamentos que seriam tomados por seus estudantes ao longo do processo. Entretanto, por se tratar de uma atividade que propicia um ambiente de aprendizagem investigativo alguns imprevistos poderiam surgir. Sobre isso Ana afirmou o seguinte:

Ana: Eu tinha medo de surgir algum conteúdo, alguma coisa que não sabia responder, algum encaminhamento...vamos supor, o aluno está indo por um caminho e você está vendo que está errado. Como eu vou orientar ele, sem dar resposta? Eu...situações que podem acontecer em sala de aula que o professor fica com medo de não conseguir dar conta, de envolver outro conteúdo de uma outra área.

(Entrevista 5 - janeiro, 2016).

Esses questionamentos e reflexões revelados na fala de Ana, explicitam a relevância do desenvolvimento de práticas pedagógicas com Modelagem na docência para que se possa superar obstáculos e resistências, como os apontados por Ceolim (2015), quanto a presença da Modelagem na Educação Básica. A experiência de Ana atribui-lhe confiança a cada nova aula, tanto que já se mostrava, e afirmava-se, confiante ao fim da atividade empreendida no TCC. Segundo a futura professora, a prática e reflexão sobre a mesma, conferiram-lhe segurança para empreender atividades investigativas nas suas aulas no exercício da profissão.

\section{4 À guisa de conclusão: algumas relações entre as aprendizagens sobre a prática pedagógica com Modelagem Matemática e a participação em comunidades sociais}

Nesse texto objetivamos discutir sobre o papel das participações de futuros professores de Matemática em diferentes comunidades sociais no processo de aprendizagem sobre a prática pedagógica com Modelagem Matemática. Para tanto, assumimos que a aprendizagem é a mudança de padrões de comportamento em comunidades sociais e recorremos a descrições e análises de episódios de sala de aula e entrevistas desenvolvidas com estudantes que cursavam o quarto ano de Licenciatura em Matemática em uma universidade pública paranaense no ano letivo de 2015. Mais particularmente, consideramos as participações de duas futuras professoras, Clara e Ana, em uma comunidade social constituída em uma disciplina de Modelagem Matemática e as relações estabelecidas pelas estudantes entre a 
prática dessa comunidade às outras às quais pertenciam.

No caso de Clara, consideramos a participação em uma comunidade escolar na qual era professora, e no caso de Ana a participação em uma comunidade escolar por meio do PIBID e em decorrência do desenvolvimento do seu TCC. Nesse sentido, Clara e Ana podem ser reconhecidas como brokers, pois, como indica Wenger (1998), buscaram conectar práticas das comunidades às quais pertenciam procurando inserir elementos de uma prática em outra. Essas conexões foram possíveis porque as comunidades sociais consideradas no processo analítico são fronteiriças, com membros, como Ana e Clara, e objetos, como o currículo, comuns. Os domínios e práticas das comunidades, no entanto, eram distintos, o que tornou a busca por inserir práticas de uma comunidade em outra, mais ou menos complexos para as licenciandas.

No que se refere à prática pedagógica com Modelagem Matemática, enquanto a comunidade da disciplina de Modelagem foi sustentada num domínio que amparou ações com objetivo de evidenciar motivos favoráveis à sua incorporação à prática profissional docente, a comunidade escolar da qual Clara fazia parte pareceu sustentar-se num domínio alinhado a práticas educacionais tradicionais, que representam obstáculos para a presença da Modelagem. Nesse sentido, a participação de Clara e seus modos de pertencimento à comunidade escolar pareceram ser preponderantes ao seu pertencimento à comunidade da disciplina de Modelagem, conduzindo a posicionamentos que vão ao encontro da decisão de não incorporar práticas de Modelagem à sua prática profissional. A dificuldade por mudanças nos padrões de participação de Clara na comunidade escolar no que se refere à prática pedagógica com Modelagem pode estar relacionada à complexidade da aproximação entre as práticas da constelação de práticas a que pertencia. Como afirmam Vilas Boas e Barbosa (2016), quando práticas estão mais próximas, a ação do broker torna-se menos complexa e admite a ocorrência de mudanças no padrão de participação. Isso pareceu ocorrer com Ana.

Considerando as interpretações apresentadas no decorrer do texto, a participação de Ana nas comunidades do PIBID e da disciplina de Modelagem ampararam a sua participação em uma comunidade escolar, para o desenvolvimento do seu TCC - momento em que pôde aprender na prática docente sobre a prática pedagógica com Modelagem - e permitiram que a futura professora aproximasse as práticas dessas comunidades. Esse movimento, de alinhar as práticas das comunidades às quais pertencia, evidenciando a constelação de práticas na qual era broker, tal como Ana fez, "exige suficiente legitimidade para influenciar o desenvolvimento de uma prática, mobilizar a atenção e enfrentar interesses conflitantes" (WENGER, 1998, p. 109, tradução nossa). Nesse contexto, ressaltamos a participação de Ana na comunidade social do PIBID. Essa é uma comunidade composta por futuros professores de 
Matemática (aprendizes), professores formadores e professores da Educação Básica e que permitiu à Ana a experiência na e para a docência por meio de práticas compartilhadas entre os seus participantes. Em relação à Ana, a participação nessa constelação de práticas possibilitou a (res)significação sobre a prática pedagógica com Modelagem Matemática.

Como indicamos em estudo anterior (BRAZ, 2017), contextos de formação como o PIBID e projetos extensionistas com essas características têm se mostrado ambientes formativos ricos que propiciam aprendizagens aos seus membros e, no caso dos futuros professores, encorajam o desenvolvimento de práticas pedagógicas que se distanciam das tradicionais. Isso pelo motivo de que esses ambientes formativos são potenciais para aproximar as comunidades escolar àquelas constituídas na formação inicial de professores.

Essas considerações têm implicações para a formação inicial de professores no contexto da Modelagem Matemática, pois indicam a relevância de se investir em ambientes e ações formativas que busquem alinhar práticas escolares às práticas empreendidas nos cursos de Licenciaturas. Recomendamos ainda que essas ações sejam desenvolvidas por coletivos que abarquem futuros professores, professores formadores e professores da Educação Básica.

À guisa de finalização desse texto, sinalizamos para a necessidade de pesquisas que investiguem o processo de aprendizagem sobre a prática pedagógica com Modelagem elegendo como foco as características (domínios) das comunidades nas quais essas aprendizagens são construídas, a fim de aprofundar a discussão sobre como os ambientes têm permitido e/ou influenciado os processos de aprendizagem docentes nesse contexto.

\section{Referências}

ALMEIDA, L. M. W. de; SILVA, K. A. P. da; VERTUAN, R. E. Modelagem Matemática na Educação Básica. São Paulo: Contexto, 2012.

AMADO, N. M. Participação numa constelação de práticas: iniciação dos professores de matemática à profissão docente. Revista Educação Matemática em Foco, Campina Grande, v. 6, n. 2, p. 148 - 173, jul./dez. 2017.

BARBOSA, J. C. A prática dos alunos no ambiente de Modelagem Matemática: o esboço de um framework. In: BARBOSA, J. C.; CALDEIRA, A. D.; ARAÚJO, J. L. (ed.). Modelagem

Matemática na Educação Matemática Brasileira: pesquisas e práticas educacionais. Recife: SBEM, 2007. p. 161-174.

BRAZ, B, C.; KATO, L. A. Constituição de Comunidades de Prática Locais e o Ambiente de aprendizagem da Modelagem Matemática: algumas relações. Bolema, Rio Claro, v. 29, n. 52, p. 613 636, ago. 2015

BRAZ, B. C. Aprendizagens sobre modelagem matemática em uma comunidade de prática de futuros professores de matemática. 2017. 253f. Tese (Doutorado em Educação para a Ciência e a Matemática) - Universidade Estadual de Maringá, Centro de Ciências Exatas, Maringá, 2017. 
CEOLIM, A. J. Modelagem matemática na educação básica: obstáculos e dificuldades apontados por professores. São Carlos: UFSCar, 2015.

CYRINO, M. C. C. T. Comunidades de Prática de professores como espaço de investigação sobre a formação de professores de Matemática. In: BATISTA, I. L.; SALVI, R. F. (org.). Pós-graduação em Ensino de Ciências e Educação Matemática: um perfil de pesquisas. Londrina: EDUEL, 2009. p. 95-110.

FERNANDES, E. Aprender Matemática para viver e trabalhar no nosso mundo. 2004. 494 f. Tese (Doutorado em Educação - Especialidade em Didática da Matemática) - Universidade de Lisboa, Faculdade de Ciências, Lisboa, 2004.

FIORENTINI, D.; LORENZATO, S. Investigação em Educação Matemática: percursos teóricos e metodológicos. 3. ed. Campinas: Autores Associados, 2009.

FRANCO, M. A. R. S. Prática pedagógica e docência: um olhar a partir da epistemologia do conceito. Revista Brasileira de Estudos pedagógicos, Brasília, v. 97, n. 247, p. 534-551, set./dez. 2016.

GARCIA, T. M. R. Identidade profissional de professores de matemática em uma comunidade de prática. 2014. Tese (Doutorado em Ensino de Ciências e Educação Matemática) - Universidade Estadual de Londrina, Londrina, 2014.

GARCIA, T. M. R.; CYRINO, M. C. C. T. Identidade profissional de professor de Matemática em uma Comunidade de Prática. In: ALMEIDA, L. M. W.; CYRINO, M. C. C. T.; SAVIOLI, A. M. (org.). Educação Matemática no Ensino Fundamental: Formação de professores e práticas de alunos, 2014. p. 1 - 24.

GARNICA, A. V. M. História Oral e educação Matemática. In: BORBA, M. C.; ARAÚJO, J. L. (org.). Pesquisa Qualitativa em Educação Matemática. Belo Horizonte: Autêntica, 2012. p. 87-109.

KAISER, G.; SRIRAMAN, B. A global survey of international perspectives on modelling in mathematics education. Zentralblatt für Didaktik der Mathematik, London, v. 38, n. 3, p. 302-310, 2006.

LAVE, J. Cognition in Practice: Mind, mathematics and culture in everydat life. Cambridge: Cambridge University Press, 1988.

LAVE, J.; WENGER, E. Situated Learning: Legitimate Peripheral Participation. Cambridge: Cambridge University Press, 1991.

LAVE, J. Aprendizagem como/na prática. Horizontes Antropológicos, Porto Alegre, ano 21, n. 44, p. 37-47, jul./dez. 2015.

MATOS, J. F. Aprendizagem e Prática Social: Contributos para a Construção de Ferramentas de Análise da Aprendizagem Matemática Escolar. In: ESCOLA DE VERÃO, 2., 1999, Santarém. Actas... Santarém: Sociedade Portuguesa de Ciências da Educação, 1999. p. 65-94.

MEYER, J. F. C. A.; CALDEIRA, A. D.; MALHEIROS A. P. S. Modelagem em Educação Matemática. Belo Horizonte: Autêntica; 2011.

MUTTI, G. S. L.; KLÜBER, T. E. Aspectos que constituem práticas pedagógicas e a formação de professores em Modelagem Matemática. Alexandria, Florianópolis, v. 11, n. 2, p. 85 - 107, nov. 2018. 
OLIVEIRA, W. P. Modelagem Matemática nas Licenciaturas em Matemática das Universidades Estaduais do Paraná. Dissertação (Mestrado em Educação: Ensino de Ciências e Matemática) Universidade Estadual do Oeste do Paraná, Cascavel, 2016.

OLIVEIRA, W. P. Prática de modelagem matemática na formação inicial de professores de matemática: relato e reflexões. Revista Brasileira de Estudos Pedagógicos, Brasília, v. 98, n. 249, p. 503-521, 2017.

OLIVEIRA, W. P.; KLÜBER, T. E. Componente Curricular de Modelagem Matemática: um Olhar para as Instituições Universitárias Estaduais do Paraná. Acta Scientiae Canoas, Canoas, v. 20, n. 5, p.813-830, set./out. 2018.

SCHOMMER, P. C. Comunidades de prática e articulação de saberes na relação entre Universidade e Sociedade. 2005. Tese (Doutorado em Administração de empresas) - Escola de Administração de Empresas de São Paulo, São Paulo, 2005.

SKOVSMOSE, O. Cenários para investigação. Bolema, Rio Claro, v. 13, n. 14, p. 66 - 91, 2000.

TARDIF, M. Saberes docentes e formação profissional. 4. ed. Petrópolis: Vozes, 2004.

VILAS BOAS, J.; BARBOSA, J. C. Aprendizagem do professor: uma leitura possível. Ciência e Educação, Bauru, v. 22, n. 4, p. 1097-1107, 2016.

WENGER, E. Communities of Practice: Learning, Meaning, And Identity. New York: Cambridge University Press, 1998.

WINBOURNE, P.; WATSON, A. Participating in Learning Mathematics Througt Shared Local Practices in the Classrooms. In: WATSON, A. (ed.). Situated Cognition and the Learning of Mathematics. Oxford: Centre for Mathematics Education Research of the University of Oxford, 1998. p. 93-104.

Submetido em 01 de Setembro de 2019. Aprovado em 05 de Agosto de 2020. 